\title{
Aortic valve ring annuloplasty is an option in left ventricular assist device patients
}

\author{
Yaron D. Barac, MD, PhD, ${ }^{a}$ Anthony W. Castleberry, $\mathrm{MD},{ }^{\mathrm{a}}$ Chetan B. Patel, MD, ${ }^{\mathrm{b}}$ \\ Sharon L. McCartney, MD, FASE, ${ }^{\mathrm{c}}$ and Jacob N. Schroder, MD, ${ }^{\mathrm{a}}$ Durham, NC
}

\footnotetext{
From the a Division of Cardiovascular and Thoracic Surgery, ${ }^{\mathrm{b}}$ Division of Cardiology, Department of Internal Medicine, and ${ }^{c}$ Division of Cardiothoracic Anesthesiology, Department of Anesthesiology, Duke University Medical Center, Durham, NC.

Disclosures: Authors have nothing to disclose with regard to commercial support.

Received for publication Aug 24, 2018; revisions received Oct 16, 2018; accepted for publication Oct 26, 2018; available ahead of print Jan 8, 2019.

Address for reprints: Yaron D. Barac, MD, PhD, Duke University Medical Center, 10 Duke Medicine Cir, Durham, NC 27710 (E-mail: yaron.barac@duke.edu).

J Thorac Cardiovasc Surg 2019;157:e381-3

$0022-5223 / \$ 36.00$

Copyright (C) 2018 by The American Association for Thoracic Surgery

https://doi.org/10.1016/j.jtcvs.2018.10.149
}

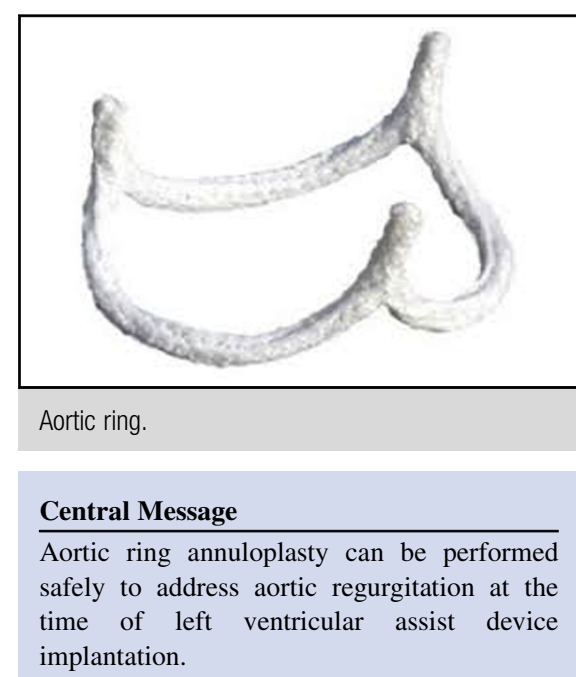

See Commentary on page e 385 .
Aortic valve regurgitation (AR) complicates the efficacy of continuous-flow left ventricular assist device (LVAD) therapy and is known to worsen with duration of LVAD support, negatively affecting the unloading effect of LVAD therapy. ${ }^{1}$ Multiple techniques have been described to address AR in LVAD recipients, including transcatheter techniques, central coaptation stitch, patch closure, and valve replacement. $^{2}$ Case series on these techniques lack sufficient sample size to comment on the optimal timing of intervention. Intervention on the aortic valve at the time of LVAD implantation has been described as a possible method for decreasing postimplantation AR progression. ${ }^{3}$ Because the pathophysiology of AR in this setting includes annular dilation, newer techniques that target annular dilation, such as internal geometric annuloplasty ring insertion, represent a potential treatment strategy in this population. ${ }^{3,4}$ We present the first documented case in which use of an aortic ring annuloplasty at the time of LVAD implantation was performed.

\section{CASE PRESENTATION}

A 70-year-old male patient with nonischemic cardiomyopathy and end-stage heart failure was admitted to the hospital for progressive functional deterioration and worsening end-organ function. The decision was made to offer the patient an implantable left ventricular assist device as destination therapy. His preoperative echocardiogram demonstrated a trileaflet aortic valve with central malcoaptation, resulting in mild $\mathrm{AR}$ and a patent foramen ovale
(Figure 1). After performance of a median sternotomy and placement of the patient on cardiopulmonary bypass, the heart was arrested with antegrade cardioplegia and a low transverse aortotomy was made to expose the aortic valve. The valve was a trileaflet valve with some leaflet laxity but no other structural abnormalities, so the decision was made to proceed with aortic valve ring annuloplasty and closure of the patent foramen ovale. The leaflets were sized, and a 21-mm ring (HAART 300 Aortic Annuloplasty Device; Biostable Science \& Engineering Inc, Austin, Tex), was chosen. Three commissural ring annuloplasty sutures were placed and brought through the ring posts. The ring was then put into position and secured at the nadirs of the annulus with 3 more stiches (Video 1). The aortotomy was then closed in 2 layers, and the crossclamp was removed after adequate de-airing procedures. A HeartWare ST HVAD (HeartWare International Inc, Framingham, Mass) was then implanted in the standard fashion, with inflow through the left ventricular apex and the outflow graft anastomosed to the ascending aorta. Completion echocardiography at the end of the case demonstrated trace AR (Figure 1). The crossclamp time in this case was 76 minutes (average Society of Thoracic Surgeons aortic valve replacement times are 60-70 minutes), and the total bypass time was 151 minutes (this time is expected to be reduced to approximately 30 minutes in future cases). The chest was closed, and the patient was transferred to the intensive 


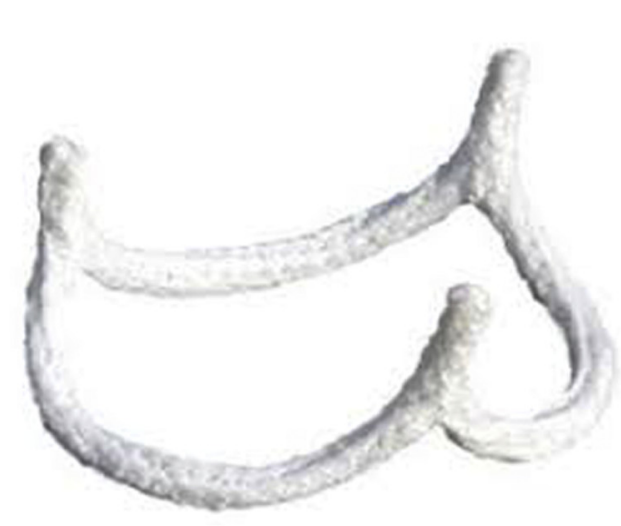

A
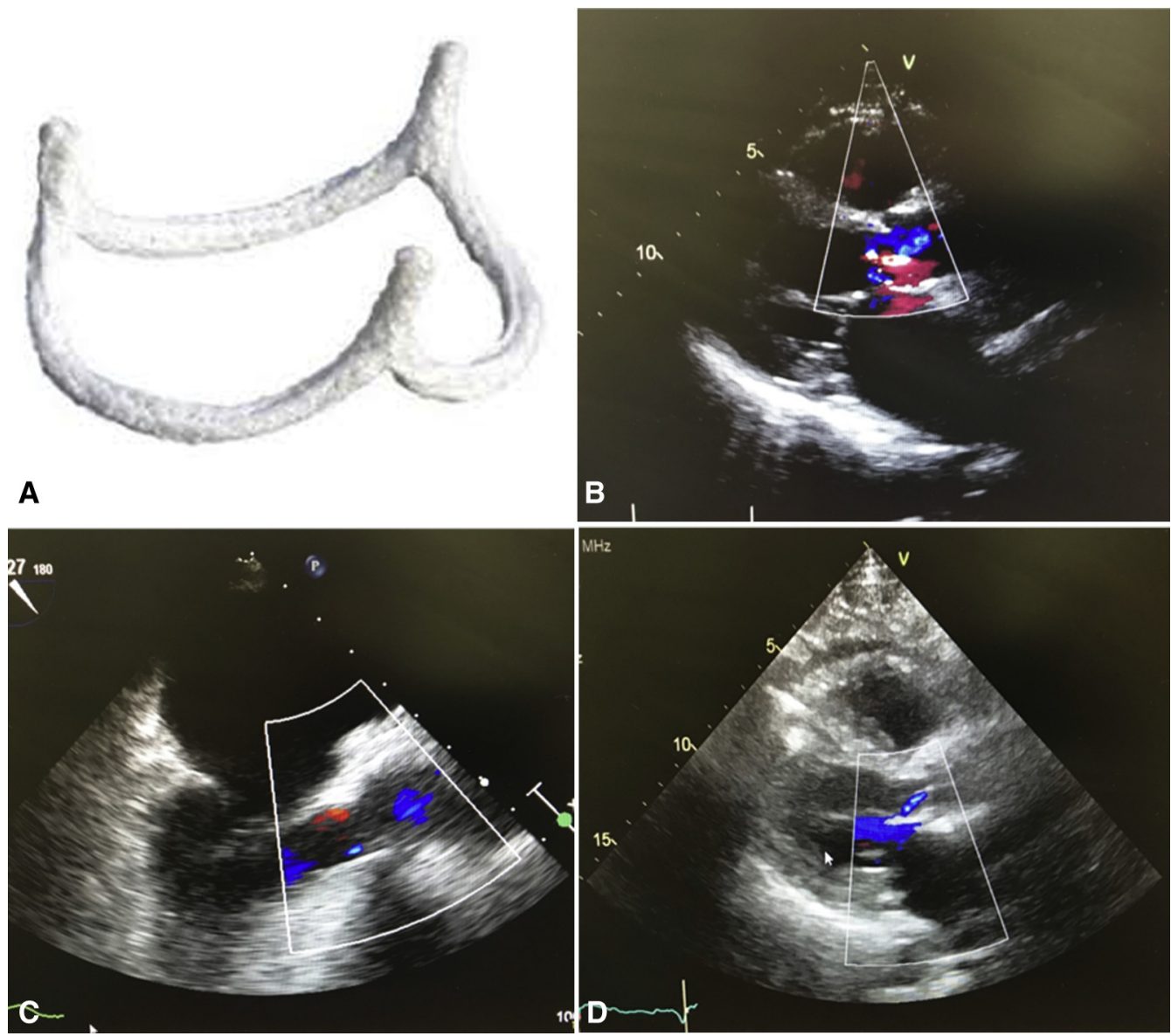

FIGURE 1. A, HAART 300 Aortic Annuloplasty Device (Biostable Science \& Engineering Inc, Austin, Tex; picture adapted from Biostable Science \& Engineering Inc Web site). B, Transthoracic echocardiogram, parasternal long-axis view demonstrating the preoperative aortic regurgitation of a patient being evaluated for left ventricular assist device implantation. Mild aortic regurgitation can be seen (yellow area in the center, representing turbulence flow). C, Intraoperative transesophageal echocardiogram, midesophageal long-axis view, demonstrating the aortic valve ring with trace aortic regurgitation after cessation of cardiopulmonary bypass after left ventricular assist device and aortic ring implantation, demonstrating the efficacy of the aortic valve repair. D, Transthoracic echocardiogram, parasternal long-axis view demonstrating the competency of the aortic valve repair with trace aortic regurgitation 2 months postoperatively, with left ventricular assist device functioning well, demonstrating the durability of the aortic valve repair.

care unit in stable condition. The postoperative course was uneventful, and he was discharged home 7 days after surgery. A routine transthoracic echocardiogram obtained

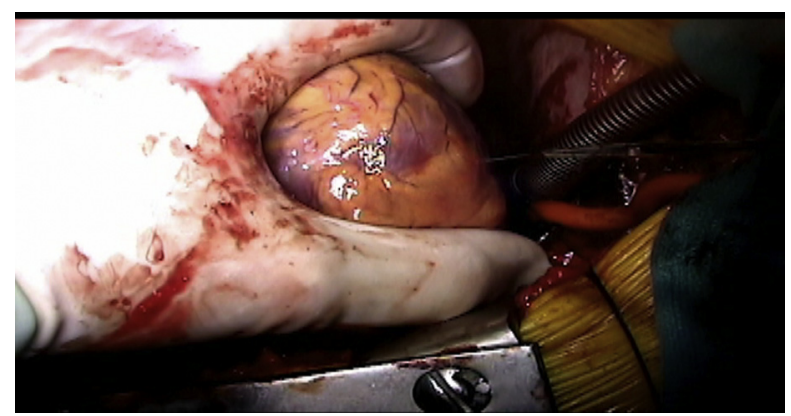

VIDEO 1. Aortic ring implantation: performing aortotomy, sizing the ring, putting in the stitches, and implanting the ring. Video available at: https://www.jtcvs.org/article/S0022-5223(18)33123-4/fulltext.
2 months after the operation demonstrated continued resolution of the AR (Figure 1).

\section{DISCUSSION}

Aortic regurgitation is a significant complication of LVAD implantation, because it creates a closed loop, reduces the cardiac output, and therefore reduces the LVAD efficiency. AR development (mild or greater) affects as many as $50 \%$ of LVAD recipients and has an impact on patient survival as well as quality of life. ${ }^{5}$ Numerous conditions during LVAD support favor the development of AR, so repair of preexisting AR, including mild AR, should be considered. There are several available options for addressing AR at the time of surgery (central coaptation stitch, valve replacement, etc); however, these methods either require a prolonged crossclamp time or have questionable efficacy. Ring annuloplasty is a novel option that addresses AR with a relatively short crossclamp time (eventually, after 
the learning curve). Although ring annuloplasty requires a longer crossclamp time than does a central coaptation stitch, its efficacy has been proved and tested in patients without LVAD support. ${ }^{4}$ This procedure still requires the use of cardioplegia and crossclamping and therefore may still affect postoperative right ventricular function; because longer cross clamp time carry a greater risk of right ventricular failure, however, this procedure is expected to have an advantage relative to valve replacement. During the debate regarding what is best for the patient-replacing the valve with a bioprosthetic valve or repairing it with the ringone should remember that with the ring, the patient will have less prosthetic material and thus less risk of infection. Even more important for the patient with LVAD support, keeping the native leaflets reduces the risk of leaflet adhesion to each other when the aortic valve is not opening.

The anticipated duration of LVAD support for each patient should be part of the decision-making process. Addressing mild AR with a relatively simple and effective solution should be considered in patients undergoing
LVAD placement as destination therapy or as a bridge to transplant with an expected long wait time for an available organ.

The novel aortic ring offers a new treatment option for an old dilemma in treating patients in heart failure undergoing implantation of an LVAD. Future investigations encompassing multicenter, controlled studies should be conducted.

\section{References}

1. Rajagopal K, Daneshmand MA, Patel CB, Ganapathi AM, Schechter MA, Rogers JG, et al. Natural history and clinical effect of aortic valve regurgitation after left ventricular assist device implantation. J Thorac Cardiovasc Surg. 2013;145:1373-9.

2. Atkins BZ, Hashmi ZA, Ganapathi AM, Harrison JK, Hughes GC, Rogers JG, et al. Surgical correction of aortic valve insufficiency after left ventricular assist device implantation. J Thorac Cardiovasc Surg. 2013;146:1247-52.

3. Holtz J, Teuteberg J. Management of aortic insufficiency in the continuous flow left ventricular assist device population. Curr Heart Fail Rep. 2014;11:103-10.

4. Mazzitelli D, Fischlein T, Rankin JS, Choi YH, Stamm C, Pfeiffer S, et al. Geometric ring annuloplasty as an adjunct to aortic valve repair: clinical investigation of the HAART 300 device. Eur J Cardiothorac Surg. 2016;49:987-93.

5. Kalathiya RJ, Grinstein J, Uriel N, Shah AP. Percutaneous transcatheter therapies for the management of left ventricular assist device complications. J Invasive Cardiol. 2017;29:151-62. 